\title{
Physiological Barriers to Communication within Organizations
}

\author{
Mustafa Altun \\ English Language Teaching Department, Tishk International University, Erbil, Iraq \\ mustafa.altun@tiu.edu.iq \\ Elaf Nejad Anwar \\ English Language Teaching Department, Tishk International University, Erbil, Iraq
}

\author{
DOI: 10.47299/bsjmm.v2i1.66
}

\begin{abstract}
Through communication, we can express our ideas and thoughts. The objective of this research is to look at the interpersonal communication process. Interpersonal communication is defined as the interchanging of information between two or even more individuals. This paper will emphasize physiological barriers in communication. Physiology relates to how well our body mechanisms function. If our body mechanism is not functioning optimally, it can lead to difficulty in communication. During the communication process, there are certain factors that might hamper effective communication. These elements which interfere with the passing of information are known as barriers. As such, physiological barriers in communication can be defined as the inability of an individual to pass information to another person due to his physical condition. The research is going to focus on physiological barriers in communication. Additionally, a critical analysis of past case studies will also be looked at. The research method that is going to be used is looking at the past case study. The study is vital as it will help us find the root cause for physiological barriers in communication in an organization and ways of overcoming them. With greater communication, an organization will be more productive.
\end{abstract}

Keywords: Psychological, Barriers, Communication, Obstruction, Mental

\section{Introduction}

Communication is vital in every aspect of life and plays a key role in the expression of oneself. Consequently, communication can be defined as the process of passing information from one medium to another. Other scholars and researchers have described communication as the science of imparting information. It is a delicate process as some occurrence can take place; hence, affecting the desired effect of communication technology has brought up many ways of communication different from the traditional ones. Initially, one would be sent letters, but now one can send an email with a click of a button. One can pass information from one continent to another via video conferencing (Abdin, 2013). If one passes the information from one medium to the other, and it does not reach its intended target, the information is rendered redundant. For instance, one can send a message in a noisy area; thus, the receiver will not clearly understand it.

\section{Physiological Barriers in Communication}

Anything that hinders the passing of information efficiently is a barrier. A barrier can be caused by a couple of things; the environmental barriers, semantic barriers, socio-psychological barriers, and physiological barriers. This paper will emphasize the physiological barriers in communication. Physiology relates to how well our body mechanisms function. If our body mechanism is not functioning optimally, it can lead to difficulty in communication. As such, physiological barriers in communication can be defined as the inability of an individual to pass information to another person 
due to his physical condition. The physical condition here relates to performing bodily functions. They include sensory and physical dysfunction. For information to be imparted effectively, the sender and receiver's senses should function congruously (Abdin, 2013). For example, if anybody part of an individual is not performing, the information will not reach the recipient.

\section{Causes of Physiological Barriers in Communication}

If the person responsible for hearing the communication is impaired aurally, then it means he cannot acquire the audio message. The same applies to the sender. If the sender is aurally impaired, he will not be able to receive any audio feedback. As such, this condition is a major impediment to productive communication. Visual impairment is also another form of physiological barrier that can impact communication. Eye contact plays a pivotal role when communicating. Visual impairment can be caused by conditions such as myopia. We also have speech disorders as an obstacle to communication. As a tool of communication, speech plays a significant role in communicating. Some of the orders make fluidity of communication difficult, while in others, one cannot communicate altogether. For information to be received and interpreted well, it needs to be clear. A disorder like stuttering will interfere with clarity. Example of speech disorders include muteness and apraxia. Selective perception is another form of physiological barrier to communication. It relates to an individual state of mind during the time of communication. One might have been undergoing emotional trauma, thus cannot intercept or pass the information efficiently. An individual mind tends to stray away in such a situation. For instance, when one is involved in a car accident, and the police are inquiring information from him, he might be disoriented. The above scenarios can hamper communication. Some other individuals have a poor memory. They cannot retain what they have been told for long. Such people will forget to send back feedback as they have forgotten it altogether. As such, the retaining of information is key for communication to take place smoothly. Lastly, we have the physical condition aspect. It is also a physiological barrier to communication as it interferes with the functioning of the body mechanism. When one is suffering from an ailment, he cannot communicate fluidly. Some organs which are keys in communication might have been affected by the disease. When one is sick, the method via which communication is passed can be changed, thus affecting the quality of information. Also, when one has a sore throat, the voice's clarity is affected; thus, the recipient might not get the required information.

\section{Literature Review}

This part will look at what other researchers have done relating to the research question. According to Kapur (2018) communication is a continuous process that occurs daily in our lives. Be it in offices or at home; communication will take place. Thus, it is a vital skill in an organization (Budur, 2018, 2020; Mohammed et al., 2020; Poturak et al., 2020). It is a vital skill that one can acquire by observation or self-taught. Kapur (2018) further expounds on how cultivation theory is a major physiological impediment to effective communication. In cultivation theory, the mass media influences the perception of people, and they begin forming a biased opinion, which affects their communication. They take whatever is shown on the popular media to be a true and correct replica of what is happening on the ground (Kapur, 2018).

Listening is important when exchanging information from one person to another (Demir and Bulut, 2018; Mart, 2020). It helps one capture the information being relayed to him. According to Luft (2001) the deaf usually has a hard time interacting and communicating in an organization which leads to poor 
interpersonal communication (Demir et al., 2019, 2020; Torlak, 2019, 2021). As such, it is difficult for the deaf to keep employment as lack of understanding means they respond inappropriately to instructions (Mohammed et al., 2020; Zaim et al., 2020). This makes it harder for them to flourish career-wise (Luft, 2001). Communication skills are vital for them to relate well with their colleagues and perform their tasks (Budur and Demir, 2019). The setting within an organization can also be a barrier to effective communication for the aurally impaired (Budur and Poturak, 2020). Without limiting ourselves to human beings only, most scholars define communication as the way of conveying messages or any other information from one point to another (Budur and Poturak, 2021; Khan and Yildiz, 2020; Top et al., 2020). All living creatures have their own unique way of conveying or passing messages. This communication can take different forms such as words, symbols, expressions, and finally, gestures (Habermas, 2015; Serin, 2018). Through communication, all living things have coexisted peacefully for centuries and will continue like so even soon.

Originally, communication is coined from a Latin word, communism, which simply means common. This aligns with its purpose because without commonness of language and understanding communication cannot take place. Since communication unites people with their environment, human beings are subject to influence by other people's beliefs as well as ideas over time as human beings continue to interact with one another (Habermas, 2015).

In modern-day organizations, communication is very crucial in the fulfillment of the company's mission, vision, and goals. Therefore, organizations have established proper communication channels that are to be observed when employees are undertaking their duties as assigned in their job descriptions. Without communication, day to day activities will be interfered with not only in wellestablished units such as organizations but also in the smallest units such as families. Back then, in the olden days, there is enough evidence on the interaction of human beings with their environment, especially animals (Herring, 2011). Carvings and paintings were used as symbols with the intent to pass information, especially in early civilizations such as Egypt.

In modern-day organizations, verbal communication is the primary mode of communication. In fact, for those employees that have difficulties passing out communication, they attend pieces of training to equip them with good communication skills. Today, most businesses are becoming global; every company's goal is to become known globally and to extend its services to foreign countries as much as possible to maximize their profits. Consequently, the demand for learning a foreign language has increased exponentially in the last decade, with the most popular language of choice being English (Herring, 2011).

From the definition of communication, some of the most identifiable elements of communication are included. First, for communication to occur, there must be a sender and a receiver for it to be identified as a form of communication. Secondly, any form of communication must possess some pieces of information; the information can either be a question, an answer, a feeling, or even an idea (Mehrabian, 2017). Thirdly, for communication to serve its purpose, there must be some form of commonness in denoting the sent message.

Such commonness can be due to shared language, environment, or even shared culture for one to be able to understand one another. In addition, for communication to occur, then the past information should invoke a response from the recipient. This response can take the form of behavioral changes or facial expressions (Vaughn, 2018). Finally, communication can either be verbal, which is communicated through spoken words or written texts, or through non-verbal means, which is 
communication in the form of symbols, facial expressions, signs, or even gestures. However, on dayto-day basis, even in organizations, both methods of communication happen interchangeably. If we are human beings, we behave the same when communicating, but with some degree of formality when we are communicating in business setups (Herring, 2011).

\section{Verbal Communication}

Verbal communication incorporates both usages of languages and words between individuals. This mode of communication can either take the form of written texts or orally spoken through the mouth. Consequently, while people are speaking, listening, or writing down emails, they can be said to be undertaking verbal communication (Mehrabian 2017). Most organizations use this mode of communication when passing out information because it requires immediate feedback.

\section{Non-Verbal Communication}

On the other hand, non-verbal communication utilizes mostly gestures, signs, symbols, and expressions to convey messages from one person to another person. This type of communication is most important when forming bonds during interpersonal interactions. If a person is not interested in whatever messages that you are trying to pass across, you can usually recognize the disinterest through her behaviors (Vaughn, 2018). However, on the other end, if someone is interested in the conversation, you are most likely to know that there will be a presence of smiles and laughs. Internal communication is the flow of information within an organization; this flow of information can either be formal or informal in nature. Consequently, based on the organization's rules and procedures, we can further subdivide communication into external and internal communication, informal and formal communication, upward and downward communication, diagonal and horizontal communication, and finally, grapevine communication. Internal communication is the flow of information within an organization (Mehrabian, 2017).

On the other hand, external communication is the flow of information outside the organization. Formally, it is considered ethical to use formal communication when officially on duty. The downward form of communication happens when information trickles down from a superior employee to the junior staff of the company (Herring, 2011). However, communication is the passing of information from the junior staff to the senior staff of the management. Horizontal communication is the passing of information between two employees who are of the same ranks in the organization. However, the diagonal form of communication is a formal form of communication that doesn't recognize the set hierarchy of communication within an organization (Bell, 2016). For instance, a salesperson can be required to pass information directly to the company's vice president, depending on the circumstances.

\section{Barriers to Effective Communication}

Information can also get distorted, making the information that was supposed to be put across to be misunderstood thereof. Some of the most forms of communication barriers include physical barriers. Physical barriers such as the use of outdated equipment can be a huge barrier to communication effectiveness; one may not be able to send or receive messages as expected. Secondly, poor system designs might also be a hindrance to effective communication (Vaughn, 2018). If an organization 
establishes a rather poor flow of communication structure, there may be confusion among the employees, which might result in poor performance.

In addition, attitude may also hinder effective communication in that one may not concentrate when information has been passed out by another fellow employee's sentences (Griffin, 2006). Therefore, it is important that employees maintain a healthy working relationship between themselves to avoid such self-inflicting barriers-moreover, Ambiguity of the message also a major source of a barrier to effective communication. Ambiguity can either occur in words or in the phrasemaking up the sentences (Griffin, 2006). For instance, there are certain words that sound the same but have an entirely different meaning. If used together, the recipient of the message can get confused; therefore, such words must be avoided at all costs; another barrier to communication is personal physiological barriers.

If someone has difficulties in his or her five senses, most likely, he or she is less likely to get the right message as it was intended. In addition, gender barriers are also a contributory factor; some people may view information from certain people of a certain gender to be insignificant. Consequently, they may not pay attention to the message that is being put across, however significant the message might be. Another barrier to communication is the fear that one may be criticized by other people. This fear might prevent them from communicating effectively (Bell, 2016). It is advisable that such people be given the necessary support so that they can be confident in themselves and the ideas that they want to put across.

\section{Diffusion of Innovation Theory}

Diffusion of innovation theory can be used to explain physiological barriers in communication. According to the theory, members of the public are the ones who determine how technology is accepted by society. The mass media outlet and interpersonal communication are vital in the diffusion process. The more we adapt to innovation in an organization, the more effective the company becomes. The three core elements of the theory are channel, innovation, and the social system. For people with a physiological barrier in communication, innovation is important in coming up with practical ways of addressing their problems. The social system is the users of the innovation, such as an organization. If a new technology is introduced for the visually impaired, it will depend on certain factors to ascertain how it will be adopted. Firstly, innovation can be introduced, and an individual will decide on whether to embrace it or not. One can lack interest if he does not have full information about innovation.

The management can then persuade the person to accept the innovation as it will ease communication. After all the employee gets used to the innovation, it will be now implemented. The end-user of the innovation will by now accept it because he knows the positive and negative aspects of the innovation. The physiological barrier in communication relate to how well our body mechanism is functioning, and as such people with disability can gain a lot from this theory.

\section{Act Theory of Communication}

The adaptive concept of thought of communication relates to the acquisition of information using senses and past experiences. According to the theory, our actions are made up of steps and processes. Individuals with disabilities such as blind, deaf are the ones who suffer the most. They might find it difficult to convey information in a conventional way. On the brighter side, the activities which they are engaged in are repetitive and can stick to one's memory. A practical example is that we have 
different memory capabilities. Some people cannot store a lot of information, while others can. With this theory, we can ascertain which employees are able to store a lot of information and exchange it correctly without distortion.

\section{Computer-Mediated Communication}

In this theory, we look at interpersonal communication between two individuals via an electronic device. People can use computers to relay information and express their feelings. With the aid of software, one can interact despite one's physiological condition. There are applications that can be used by the deaf or blind. The problem with computer-mediated communication it is easy for one to deceive another. Thus, information exchanged might be biased.

\section{Cultivation Theory}

Communication is a continuous process that occurs daily in our lives. Be it in offices or at home, and communication will take place. Thus, it is a vital skill in an organization. It is a vital skill that one can acquire by observation or self-taught. Kapur (2018) further expounds on how cultivation theory is a major physiological impediment to effective communication. In cultivation theory, the mass media influences the perception of people, and they begin forming a biased opinion, which affects their communication. They take whatever is shown on the popular media to be a true and correct replica of what is happening on the ground (Kapur, 2018).

\section{Application of the Theories}

One important way of overcoming a physiological barrier in communication is by applying the diffusion of innovation theory. Innovation will allow people with disabilities to communicate better. Thus, organizations should train and have developed programs that will enhance communication for people with such disabilities.

Human beings are not perfect, and when a receiver has not understood the information being exchanged, he should seek clarification from the sender. A person with a short memory should always write short notes of the information to remember. By use of the ACT theory of communication, the management will be able to know who is best suited to transfer specific information.

\section{Discussion}

For people who cannot maintain a lot of information at once, their work overload should be reduced. Whenever an employee makes a mistake in the communication process leading to distortion of information, a constructive channel of feedback should be provided. If the feedback is negative and delivered wrongly, it will have an adverse effect on the employee. An employee's state of mind should be considered before allowing him to pass information from one person to the other. His physical wellbeing should also be considered. If he gives out a speech, he should not have a sore throat; otherwise, the information will not achieve its objective.

Human beings are not perfect, and when a receiver has not understood the information being exchanged, he should seek clarification from the sender. A person with a short memory should always write short notes of the information to remember. It is also important for the sender to be conscious of how the receiver will react to the message being passed. Some people cannot handle emotional messages. 
Communication plays an integral role in an organization. It is paramount to note that effective communication is primary to the development of an organization and essential in our daily lives. We depend on communication to carry out our daily activities as individuals. Furthermore, for an organization to achieve its objective, the information should always be delivered to the required person. For instance, if a memo sent to the accounts department from the procurement department is not delivered on time, it might incur losses. The physiological barrier in communication mainly entails the functioning of the body. As such, the management should ensure people with disabilities are well facilitated to carry out their duties. A company cannot discriminate against people on the grounds of their physical condition. In case employees are facing any trauma that might affect their communication, the company should ensure counseling services are availed to the workers. Therefore, an organization should ensure that physiological barriers of communication are eradicated. This will enhance productivity and reduce conflict within the company. Policies should be put in place to ensure there is effective communication. These policies should be reviewed annually as technologies and means of exchanging information changes all the time.

Listening is important when exchanging information from one person to another. It helps one capture the information being relayed to him. According to (Luft, 2001) the deaf usually has a hard time interacting and communicating in an organization leading to poor interpersonal communication. As such, it is difficult for the deaf to keep employment as lack of understanding means they respond inappropriately to instructions. This makes it harder for them to flourish career-wise (Luft, 2001). Communication skills are vital for them to relate well with their colleagues and perform their tasks. The setting within an organization can also be a barrier for effective communication for the aurally impaired-the physiological barriers in communication for the deaf start at birth. For a Childs language and communication skills to develop, there must be linguistic exposure. To cater to these inadequacies, Luft (2001) advocates for eccentric personnel training. This will help in alleviating the communication barrier.

\section{Conclusion}

Communication plays an integral role in an organization, not only at work but also when socializing among your peers. Being able to communicate is very important because one will be able to convey the right message and be assured that the right message has been received well by the recipient. It is paramount to note that effective communication is primary to the development of an organization and essential in our daily lives. Therefore, an organization should ensure that physiological barriers of communication are eradicated. This will enhance productivity and reduce conflict within the company. Policies should be put in place to ensure there is effective communication. These policies should be reviewed annually as technologies and means of exchanging information changes all the time. However, if one is not well equipped with the right communication skills, one can still attend communication skills training to be good in their writing and be confident in their public speaking. To avoid distortion of messages when communicating, it is important to avoid all the communication barriers as much as possible, and only then can communication be effective.

\section{References}

Abdin, J. (2013). The barrier of communication \& guidance of effective communication. SSRN Electronic Journal. Doi: $10.2139 /$ ssrn. 1133343 
Abdulla, N., Wrya, H., \& Durmaz, O. (2020). Green product perception in Kurdistan Region of Iraq. Black Sea Journal of Management and Marketing, 1(1), 1-15.

Bell, A. (2016). Media (mis) communication on the science of climate change and public understanding of science.

Budur, T. (2018). The impact of Al-Ghazali's virtues on organizational commitment and performance: A case Study at private education institutions in Kurdistan Region of Iraq. Icabep, Erbil-Iraq, 2, p21.

Budur, T. (2020). Impact of Transformational Leadership on Customer Satisfaction: Mediating effects of Employee Performance and Organizational Citizenship Behaviors. (Unpublished doctoral dissertation). International Burch University.

Budur, T., \& Demir, A. (2019a). Leadership effects on employee perception about CSR in Kurdistan Region of Iraq. International Journal of Social Sciences \& Educational Studies, 6(1). 142-154.

Budur, T., \& Demir, A. (2019b). Leadership perceptions based on gender, experience, and education. International Journal of Social Sciences \& Educational Studies, 6(1), 142-154.

Budur, T., \& Poturak, M. (2021). Employee Performance and Customer Loyalty: Mediation effect of Customer Satisfaction. Middle East Journal of Management.

Budur, T., \& Poturak, M. (2021). Transformational leadership and its impact on customer satisfaction. Measuring mediating effects of organisational citizenship behaviours. Middle East Journal of Management, 8(1), 67-91.

Demir A, Shawkat S, Majeed BN, Budur T. 2019. Fuzzy AHP and VIKOR to select best location for bank investment: case study in Kurdistan Region of Iraq. In Effective Investments on Capital Markets, Tarczyn'sk W, Nermend K (eds). Springer: Cham; 485-510.

Demir, A., \& Budur, T. (2019). Roles of leadership styles in corporate social responsibility to non-governmental organizations (NGOs). International Journal of Social Sciences \& Educational Studies, 5(4), 174-183.

Demir, A., \& Bulut, I. (2018). A New Model for Respected Meetings. Procedia Computer Science, 126, 1637-1655.

Demir, A., Budur, T., \& Heshmati, A. (2020). Antecedents of trust, corporate image, and switching costs: a case in telecommunication services in the Kurdistan region of Iraq. International Journal of Mobile Communications, 19(1), 5374.

Demir, A., Budur, T., Hiwa, M., \& Heshmati, A. (2021). Links between Knowledge Management and Organizational Sustainability: Does the ISO 9001 certification have an effect? Knowledge Management Research \& Practice (TKMR), Doi: $10.1080 / 14778238.2020 .1860663$

Durmaz, O. (2017). Investigation of the motivation parameters in health care establishments. International Journal of Social Sciences \& Educational Studies, 3(4), 44-53.

Fischer, D., Fischbach, K., \& Possega, O. (2016). Communication Barriers in Crisis Management. Retrieved from https://www.researchgate.net/publication/301770566_Communication_Barriers_in_Crisis_Management_A_Literature _Review

Griffin, E. M. (2006). A first look at communication theory. McGraw-Hill. (Online Scholarly Journal)

Habermas, J. (2015). Communication and the Evolution of Society. John Wiley \& Sons.

Herring, S. C. (2011, February 2). Communication Styles Make a Difference - NYTimes.com. Retrieved from https://www.nytimes.com/roomfordebate/2011/02/02/where- are-the-women-in- Wikipedia/communication-stylesmake-a- difference. Mehrabian, A. (2017). Nonverbal communication. Routledge.

Kapur, R. (2018). Barriers to Effective Communication. Retrieved from https://www.researchgate.net/publication/323794732_Barriers_to_Effective_Communication

Khan, N. U. S., \& Yildiz, Y. (2020). Impact of Intangible Characteristics of Universities on Student Satisfaction. Amazonia Investiga, 9(26), 105-116.

Luft, P. (2000). Communication barriers for deaf employees: Needs assessment and problem-solving strategies. Retrieved from 
https://www.researchgate.net/publication/11026132_Communication_barriers_for_deaf_employees_Needs_assessm ent_and_problem-solving_strategies

Mart, Ç, T. (2020). Integrating listening and speaking skills to promote speech production and language development. MEXTESOL Journal, 44(2), 1-7.

Mohammed, K. S., Rashid, C. A., Salih, H. A., \& Budur, T. (2020). The Role of Online Teaching Tools on the Perception of the Students during the Lockdown of Covid-19. International Journal of Social Sciences \& Educational Studies, 7(3), 178190.

Mohammed, S. S., Suleyman, C., \& Taylan, B. (2020). Burnout Determinants and Consequences Among University Lecturers. Amazonia Investiga, 9(27), 13-24.

Poe, M. (2011). A history of communications. Cambridge: Cambridge University Press.

Poturak, M., Mekić, E., Hadžiahmetović, N., \& Budur, T. (2020). Effectiveness of Transformational Leadership among Different Cultures. International Journal of Social Sciences \& Educational Studies, 7(3), 119-129.

Serin, H. (2018). The use of extrinsic and intrinsic motivations to enhance student achievement in educational settings. International Journal of Social Sciences \& Educational Studies, 5(1), 191-194.

Top, C., Abdullah, B. M. S., \& Faraj, A. H. M. (2020). Transformational Leadership Impact on Employees Performance. Eurasian Journal of Management \& Social Sciences. 1(1), 49-59

Torlak, N. G., Demir, A., \& Budur, T. (2019). Impact of operations management strategies on customer satisfaction and behavioral intentions at café-restaurants. International Journal of Productivity and Performance Management. Vol. 69 No. 9, pp. 1903-1924.

Torlak, N. G., Demir, A., \& Budur, T. (2021). Decision-making, leadership and performance links in private education institutes. Rajagiri Management Journal. Doi:10.1108/RAMJ-10-2020-0061.

Torlak, N. G., Kuzey, C., Dinc, MS., \& Budur, T. (2021). Links connecting nurses' planned behavior, burnout, job satisfaction and organizational citizenship behavior. Journal of Workplace Behavioral Health. Doi:10.1080/15555240.2020.1862675

Vaughn, H. (2018, September 17), Member Access Communication World. Retrieved from http://cw.iabc.com memberaccess/?redirect-cw.iabc.com/2018/10/02/4- must have-roles-for-a-winning-communication-team-structure/ \&p_id193421

Yildiz, Y., \& Budur, T. (2019). Introducing Environmental Awareness to College Students with Curricular and Extracurricular Activities. International journal of Academic Research in business and Social Sciences, 9(3)667-675.

Zaim, H., Demir, A., \& Budur, T. (2020). Ethical leadership, effectiveness and team performance: An Islamic perspective. Middle East Journal of Management, 8(1), 42-66. 